\title{
Current practice patterns of preoperative bowel preparation in colorectal surgery: a nation-wide survey by the Chinese Society of Colorectal Cancer
}

Zheng Liư ${ }^{\dagger}$, Ming Yang ${ }^{\dagger}$, Zhi-xun Zhao ${ }^{\dagger}$, Xu Guan, Zheng Jiang, Hai-peng Chen, Song Wang, Ji-chuan Quan, Run-kun Yang and Xi-shan Wang*

\begin{abstract}
Background: The optimal preoperative bowel preparation for colorectal surgery remains controversial. However, recent studies have established that bowel preparation varies significantly among countries and even surgeons at the same institution. This survey aimed to obtain information on the current practice patterns of bowel preparation for colorectal surgery in China.

Methods: A paper-based survey was circulated to the members of the Chinese Society of Colorectal Cancer (CSCC). The survey responses were collected and analyzed. Statistical analysis was performed for all the categorical variables according to the responses to individual questions.

Results: Three hundred forty-one members completed the questionnaire. Regarding surgical practice, 203 (59.5\%) performed $>50 \%$ of the colorectal operations laparoscopically or robotically; the use of mechanical bowel preparation (MBP) alone was significantly higher ( $63.5 \mathrm{vs} \mathrm{31.9 \% ;} P<0.001)$. The respondents who performed $>200$ colonic or rectal resections provided significantly more MBP alone (79.6 vs 39.1\%, $P<0.001$; 76.6 vs $43.2 \%, P<0.001$; respectively). Among hospitals with fewer than 500 beds, $52.4 \%$ of the respondents used MBP + oral antibiotics preparation $(\mathrm{OAP})$ + enema, a significantly higher percentage than the respondents of hospitals with more than 500 beds $(P<0.001)$. Nearly $40 \%$ of the respondents prescribed OAP in regimens; meanwhile, $74.8 \%$ prescribed preoperative intravenous antibiotics.
\end{abstract}

Conclusions: The study demonstrates considerable variation among members from the CSCC. These findings should be considered when developing multicenter trials and to provide more definitive answers.

Keywords: Bowel preparation, Mechanical bowel preparation, Colorectal surgery, Survey

\section{Background}

Although preoperative bowel preparation is a standard practice for the most elective colorectal surgical procedures and is routinely used, the method and practice still vary widely $[1-3]$. In the past few decades, various regimens of mechanical bowel preparation (MBP) and oral antibiotics preparation (OAP) have been widely debated

\footnotetext{
* Correspondence: wxshan1208@126.com

†Zheng Liu, Ming Yang and Zhi-xun Zhao contributed equally to this work. Department of Colorectal Surgery, National Cancer Center/National Clinical Research Center for Cancer/Cancer Hospital, Chinese Academy of Medical Sciences and Peking Union Medical College, Beijing, China
}

[4-7]. Previous investigators have suggested that MBP or OAP reduces the risk of anastomotic leaks and infectious complications $[8,9]$. It is widely accepted that MBP/OAP could help to reduce the stool burden and further reduce the bacterial counts $[10,11]$.

A recent study has added fuel to this debate. The analysis of the American College of Surgeons National Surgical Quality Improvement Program (ACS-NSQIP) indicated that the combined use of MBP/OAP was associated with significantly lower rates of postoperative complications compared with the use of other bowel preparation strategies [12]. However, a multicenter

(C) The Author(s). 2018 Open Access This article is distributed under the terms of the Creative Commons Attribution 4.0 International License (http://creativecommons.org/licenses/by/4.0/), which permits unrestricted use, distribution, and 
randomized trial of 1354 patients found that performing colorectal surgery safely without MBP was justified [13]. This is in keeping with common belief that clinical practice is not always evidence-based but is based on tradition and an individual's opinion and previous experiences [14].

Although optimal bowel preparation remains elusive, understanding these differences in practice can help continually improve the clinical practices and implement multicenter trials. To the best of our knowledge, no such

Table 1 General characteristics

\begin{tabular}{|c|c|c|}
\hline & Number & Percent \\
\hline \multicolumn{3}{|l|}{ Gender } \\
\hline Male & 318 & 93.3 \\
\hline Female & 23 & 6.7 \\
\hline \multicolumn{3}{|l|}{ Age } \\
\hline$<40$ years & 197 & 57.8 \\
\hline 40-50 years & 121 & 35.5 \\
\hline$>50$ years & 23 & 6.7 \\
\hline \multicolumn{3}{|l|}{ Working experience } \\
\hline$<10$ years & 98 & 28.7 \\
\hline $10-20$ years & 155 & 45.5 \\
\hline$>20$ years & 88 & 25.8 \\
\hline \multicolumn{3}{|l|}{ Medical specialty } \\
\hline General surgery & 169 & 49.6 \\
\hline Gastrointestinal surgery & 81 & 23.8 \\
\hline Colorectal surgery & 50 & 14.7 \\
\hline Other & 41 & 12.0 \\
\hline \multicolumn{3}{|l|}{ Hospital setting } \\
\hline General & 295 & 86.5 \\
\hline Specialized & 46 & 13.5 \\
\hline \multicolumn{3}{|l|}{ Hospital volume } \\
\hline$<500$ beds & 63 & 18.5 \\
\hline $500-1000$ beds & 87 & 25.5 \\
\hline $1000-1500$ beds & 60 & 17.6 \\
\hline$>1500$ beds & 131 & 38.4 \\
\hline \multicolumn{3}{|l|}{ Colonic resections per year } \\
\hline$<100$ & 181 & 53.1 \\
\hline $100-200$ & 62 & 18.2 \\
\hline$>200$ & 98 & 28.7 \\
\hline \multicolumn{3}{|l|}{ Rectal resections per year } \\
\hline$<100$ & 194 & 56.9 \\
\hline $100-200$ & 70 & 20.5 \\
\hline$>200$ & 77 & 22.6 \\
\hline \multicolumn{3}{|c|}{ Resection performed laparoscopically or robotically } \\
\hline$<30 \%$ & 76 & 22.3 \\
\hline $30-50 \%$ & 62 & 18.2 \\
\hline$>50 \%$ & 203 & 59.5 \\
\hline
\end{tabular}

survey of preoperative bowel preparation has been previously undertaken in China. The purpose of this study was to describe the current practice patterns of preoperative bowel preparation in colorectal surgery among members of the Chinese Society of Colorectal Cancer (CSCC).

\section{Methods}

A 19-question paper-based survey was developed (see Additional file 1). The permission to conduct the survey was obtained from the CSCC. The anonymous survey was announced by posters to the active members who attended the Annual Meeting of the CSCC on August 18-20, 2017. The participants could complete the questionnaire immediately before, during, or after the meeting, depending on their individual needs and predilections. Participation was encouraged by the program coordinators but was not mandatory.

Key demographic information was collected, including gender, age, experience time, medical specialty, affiliations, position, and volume. Specific questions were aimed at the methods and practices used for preoperative bowel preparation in colorectal surgery in the respondent's practice. The survey consisted of questions

Table 2 Answers according to bowel preparation

\begin{tabular}{lll}
\hline & Number & Percent \\
\hline Bowel preparation regimens & 173 & 50.7 \\
MBP alone & 81 & 23.8 \\
MBP + OAP + enema & 55 & 16.1 \\
MBP + OAP & 20 & 5.9 \\
Enema alone & 12 & 3.5 \\
Other & & \\
Indication for bowel preparation & 9 & 2.6 \\
Colonic resection only & 35 & 10.3 \\
Rectal resection only & 297 & 87.1 \\
Colonic resection + rectal resection & & \\
Bowel preparation for intestinal obstruction & 243 & 71.3 \\
Yes & 98 & 28.7 \\
No & & \\
Preoperative intravenous antibiotic & 255 & 74.8 \\
Yes & 86 & 25.2 \\
No & & \\
Postoperative intravenous antibiotic & 125 & 40.7 \\
Yes & 307 & 90.0 \\
No & 34 & 10.0 \\
Length of postoperative intravenous antibiotic usage & \\
> 1 days & 14 & \\
\hline MBP mechanical bowel preparation, OAP oral antibiotics preparation & \\
\hline
\end{tabular}


regarding the use of $\mathrm{MBP}$, OAP, and perioperative intravenous antibiotics for colorectal surgery. We also asked for information on whether the respondents had used bowel preparation in incomplete bowel obstruction.

Based on the responses obtained, the response rates of respondents were calculated; Fisher's exact test analysis was used to compare groups using SPSS (version 19.0; IBM Corporation, Armonk, NY).

\section{Results}

\section{Demographics}

Overall, 341 members finally completed the questionnaire, representing 31 provincial administrative regions. Table 1 shows the demographic characteristics of the respondents. There were 318 (93.3\%) male respondents and 23 (6.7\%) female respondents. Most of the respondents had more than 10 years of working experience $(71.3 \%)$, and working in general hospitals (86.5\%), and were under the age of 40 (57.8\%). The most common specialty for the respondents was general surgery (49.6\%), and 38.4\% reported working in hospitals with more than 1500 beds. Regarding the surgical volume, $28.7 \%$ performed $>200$ colonic resections per year and $56.9 \%$ performed < 100 rectal resections per year. Among the respondents, $59.5 \%$ performed $>50 \%$ of colorectal operations laparoscopically or robotically.

\section{Bowel preparation strategies}

For colorectal surgery, all the respondents routinely used preoperative bowel preparation. Approximately half of the respondents used MBP alone; MBP + OAP was used by $16.1 \%$, and MBP + OAP combined with an enema

Table 3 Subgroup analysis of preoperative bowel preparation use

\begin{tabular}{|c|c|c|c|c|c|c|}
\hline \multirow{3}{*}{$\overline{\text { Age }}$} & \multirow[b]{2}{*}{ MBP alone } & \multirow[b]{2}{*}{ Enema alone } & \multirow[b]{2}{*}{$\mathrm{MBP}+\mathrm{OAP}$} & \multirow[b]{2}{*}{$\mathrm{MBP}+\mathrm{OAP}+$ enema } & \multirow[b]{2}{*}{ Other } & \multirow[t]{2}{*}{$P$ value } \\
\hline & & & & & & \\
\hline & & & & & & \\
\hline$<40$ years & 101 & 16 & 22 & 51 & 7 & \multirow[t]{3}{*}{0.032} \\
\hline $40-50$ years & 60 & 2 & 27 & 27 & 5 & \\
\hline$>50$ years & 12 & 2 & 6 & 3 & 0 & \\
\hline \multicolumn{7}{|l|}{ Working experience } \\
\hline$<10$ years & 55 & 8 & 8 & 24 & 3 & \multirow[t]{3}{*}{0.128} \\
\hline 10-20 years & 76 & 9 & 26 & 36 & 8 & \\
\hline$>20$ years & 42 & 3 & 21 & 21 & 1 & \\
\hline \multicolumn{7}{|l|}{ Hospital setting } \\
\hline General & 148 & 16 & 49 & 72 & 10 & \multirow[t]{2}{*}{0.738} \\
\hline Specialized & 25 & 4 & 6 & 9 & 2 & \\
\hline \multicolumn{7}{|l|}{ Hospital volume } \\
\hline$<500$ beds & 10 & 6 & 13 & 33 & 1 & \multirow[t]{4}{*}{$<0.001$} \\
\hline $500-1000$ beds & 35 & 2 & 20 & 28 & 2 & \\
\hline $1000-1500$ beds & 35 & 3 & 7 & 10 & 5 & \\
\hline$>1500$ beds & 93 & 9 & 15 & 10 & 4 & \\
\hline \multicolumn{7}{|c|}{ Colonic resections per year } \\
\hline$<100$ & 61 & 11 & 40 & 62 & 7 & \multirow[t]{3}{*}{$<0.001$} \\
\hline $100-200$ & 34 & 4 & 6 & 15 & 3 & \\
\hline$>200$ & 78 & 5 & 9 & 4 & 2 & \\
\hline \multicolumn{7}{|c|}{ Rectal resections per year } \\
\hline$<100$ & 70 & 11 & 41 & 64 & 8 & \multirow[t]{3}{*}{$<0.001$} \\
\hline $100-200$ & 44 & 3 & 6 & 15 & 2 & \\
\hline$>200$ & 59 & 6 & 8 & 2 & 2 & \\
\hline \multicolumn{7}{|c|}{ Resection performed laparoscopically or robotically } \\
\hline$<30 \%$ & 20 & 3 & 16 & 35 & 2 & \multirow[t]{3}{*}{$<0.001$} \\
\hline $30-50 \%$ & 24 & 5 & 12 & 17 & 4 & \\
\hline$>50 \%$ & 129 & 12 & 27 & 29 & 6 & \\
\hline
\end{tabular}


(MBP + OAP +enema) was used by $23.8 \%$ (Table 2). No respondent used OAP alone. Enema alone and other regimens were prescribed preoperatively by 5.9 and $3.5 \%$, respectively. The percentage of the respondents performing preoperative bowel preparation for colonic resection only or rectal resection only was 2.6 and $10.3 \%$, respectively. Moreover, $71.3 \%$ of the respondents reported using bowel preparation for intestinal obstruction patients.

The respondent's age, hospital volume, volume of resections per year, and percentage of resections performed laparoscopically or robotically showed significant differences in the use of preoperative bowel preparation (Table 3). In the cohort performing $>50 \%$ of colorectal operations laparoscopically or robotically $(n=203)$, the use of MBP alone was significantly higher (63.5 vs $31.9 \%$; $P<0.001$ ) (Fig. 1). The respondents who performed $>200$ colonic or rectal resections gave significantly more MBP alone (79.6 vs $39.1 \%, P<0.001 ; 76.6$ vs $43.2 \%, P<0.001$; respectively) (Figs. 2 and 3 ). Of hospitals with less than 500 beds, $52.4 \%$ of the respondents used MBP + OAP + enema, which is significantly higher than the respondents of hospitals with more than 500 beds $(P<0.001)$ (Fig. 4). The respondent's working experience and hospital setting did not significantly affect the use of bowel preparation.

\section{OAP and intravenous antibiotics}

Preoperative oral antibiotics were administered by $39.9 \%$ of the respondents. The most common specified antibiotic drug used was metronidazole (83.9\%). Preoperative or postoperative intravenous antibiotics were administered by most respondents (74.8 vs $90.0 \%$, respectively). The length of postoperative usage was $<1$ day in $4.6 \%, 1-3$ days in $40.7 \%$, and $>3$ days in $54.7 \%$ of the respondents.

\section{Discussion}

For several decades, surgeons have utilized bowel preparation to reduce infectious complications, but the value has remained controversial. The current survey is the first nation-wide attempt to document the current trends of preoperative bowel preparation in China. Among the respondents who were older, were working in a large volume hospital, and were performing a higher percentage of minimally invasive surgeries, a significantly higher use of MBP alone was noted. This study observed variations in bowel preparation across respondents from CSCC.

The use of MBP in elective colorectal surgery is supported by emerging evidence, although several published randomized controlled trials have shown that preoperative MBP should be omitted before colon surgery $[13,15,16]$. There is ongoing debate on the role of bowel preparation in colorectal surgery, MBP is still used in routine clinical practice before both colon and rectal surgery in China, with a similar picture in the USA and Japan [17-19]. Unlike European practice, American-enhanced recovery guidelines often include MBP [20]. Why is this discrepancy evident between American and European guidelines? One possible reason may be that the European recommendation is not to be revisited at present [1].

The 2017 clinical practice guidelines from the American Society of Colon and Rectal Surgeons (ASCRS) and Society of American Gastrointestinal and Endoscopic Surgeons (SAGES) recommend MBP + OAP before colorectal surgery as preferred preparation to reduce complication rates [21]. Surveys have shown a change in the use of laparoscopic procedures compared with open procedures depending on the type of preparation used. A survey from the European Society of Coloproctology (ESCP) found that the routine use of MBP prescribed by laparoscopic surgeons was significantly lower (19.7 vs $51.5 \%$,

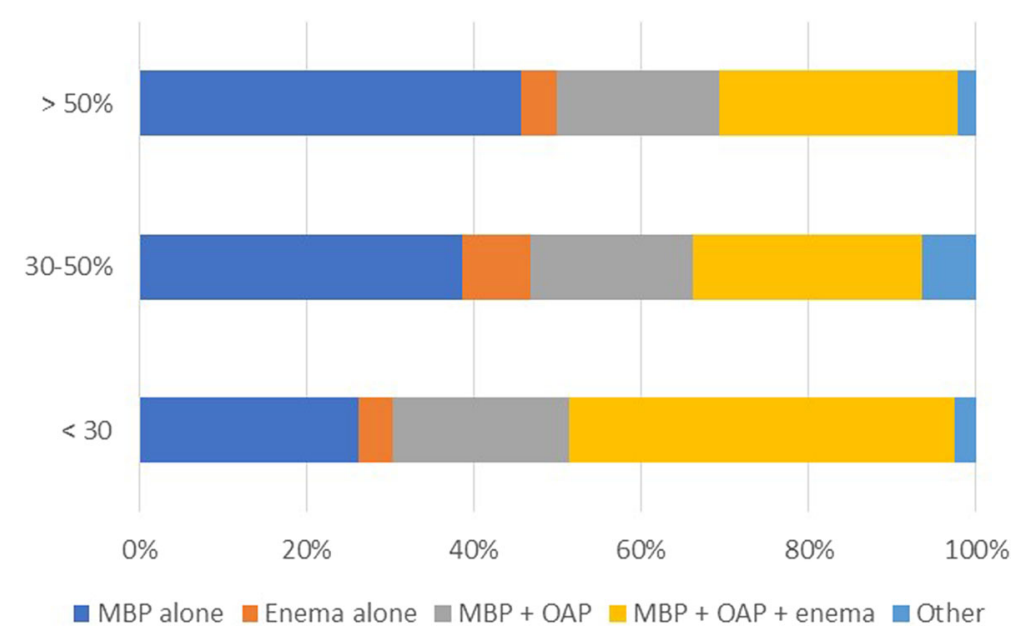

Fig. 1 Association between percentages of resections performed laparoscopically or robotically and bowel preparation. MBP mechanical bowel preparation; OAP oral antibiotics preparation 


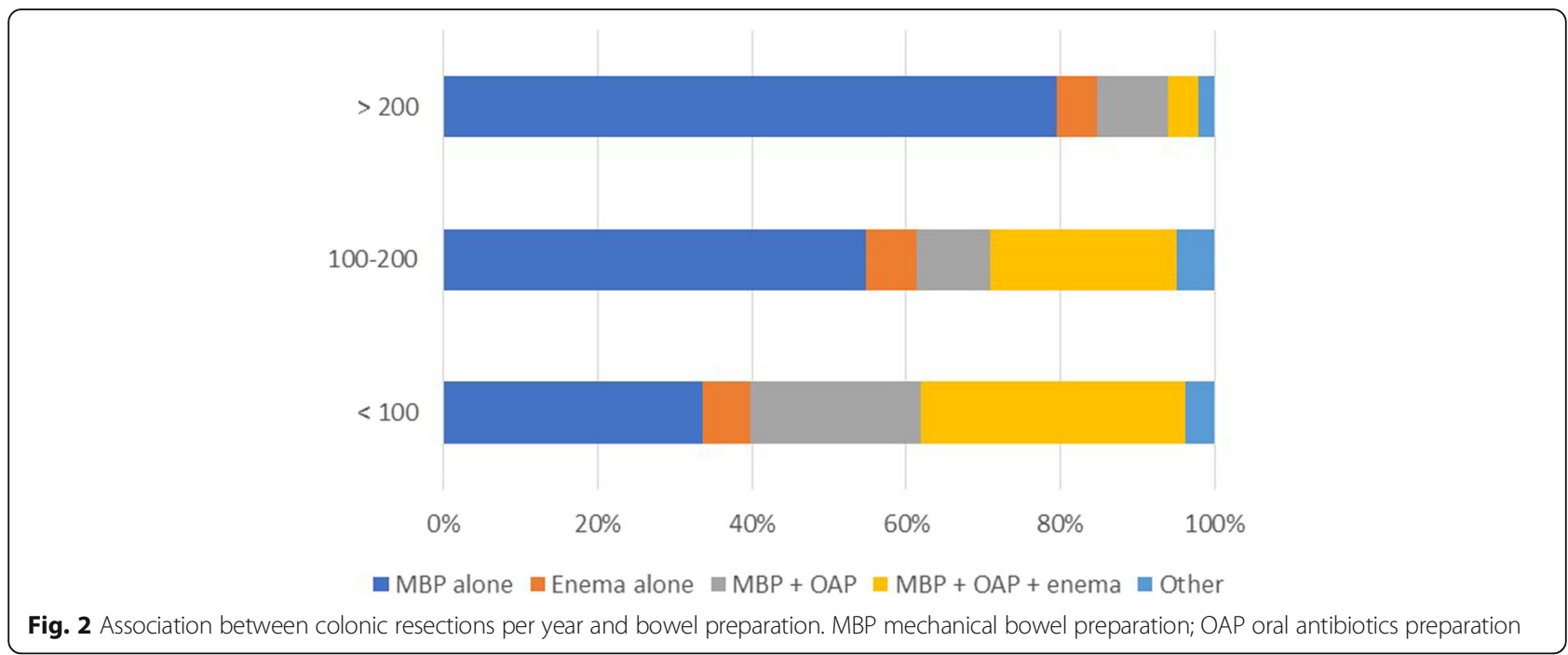

$P<0.01$ ) [22]. By contrary, a survey from the UK showed that a higher proportion of laparoscopic right-sided procedures was performed with MBP compared with open procedures (16.8 vs 9.5\%; $P=0.08$ ); however, the need for MBP for a left-sided procedure remains controversial [23]. Despite the survey limitation of unclear procedure classification in the questionnaire, this study showed a similar picture of the high use of MBP in laparoscopic or robotic surgery. Although previous studies have suggested that MBP did not improve postoperative outcomes in laparoscopic colorectal resections [24], there is an inconsistency between opinion and practice, with individual surgeons often using different regimens for their open and laparoscopic resections [23].

OAP is generally believed to help protect against infectious complication in elective colorectal resections [25]. Currently, it is becoming increasingly clear that MBP + OAP combined with intravenous antibiotics is the most effective method. Previous surveys from the USA, Europe, and Japan have shown a low rate of oral antibiotic usage [17-19, 22]. This obviously contrasts with the patterns of practice in China, because nearly $40 \%$ of the respondents prescribed OAP in regimens, meanwhile $49.3 \%$ prescribed a longer duration ( $>3$ days) of postoperative intravenous antibiotics. Our results showed that, despite the clear recommendations from the literature and the guidelines, there remains some concern about the overuse of antibiotics in China.

Moreover, in our subgroup analysis, different bowel preparation strategies are associated with hospital volume. Our results may reflect the surgeon's bias or limitations inherent in this type of survey. Regarding the lower use of OAP, our results showed that, despite the disparity among hospitals, high-volume hospitals tend to follow guidelines more closely. The other interesting finding in our study is that bowel preparation (enema)

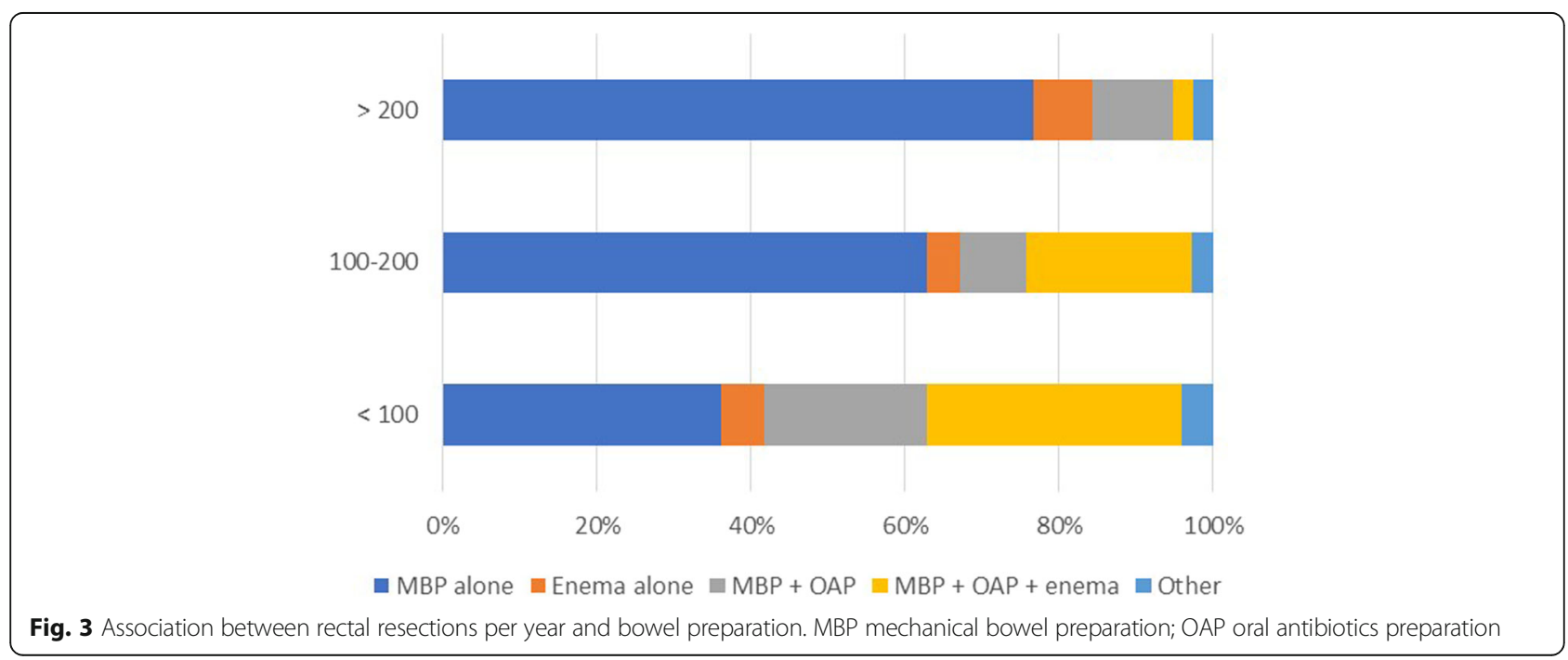




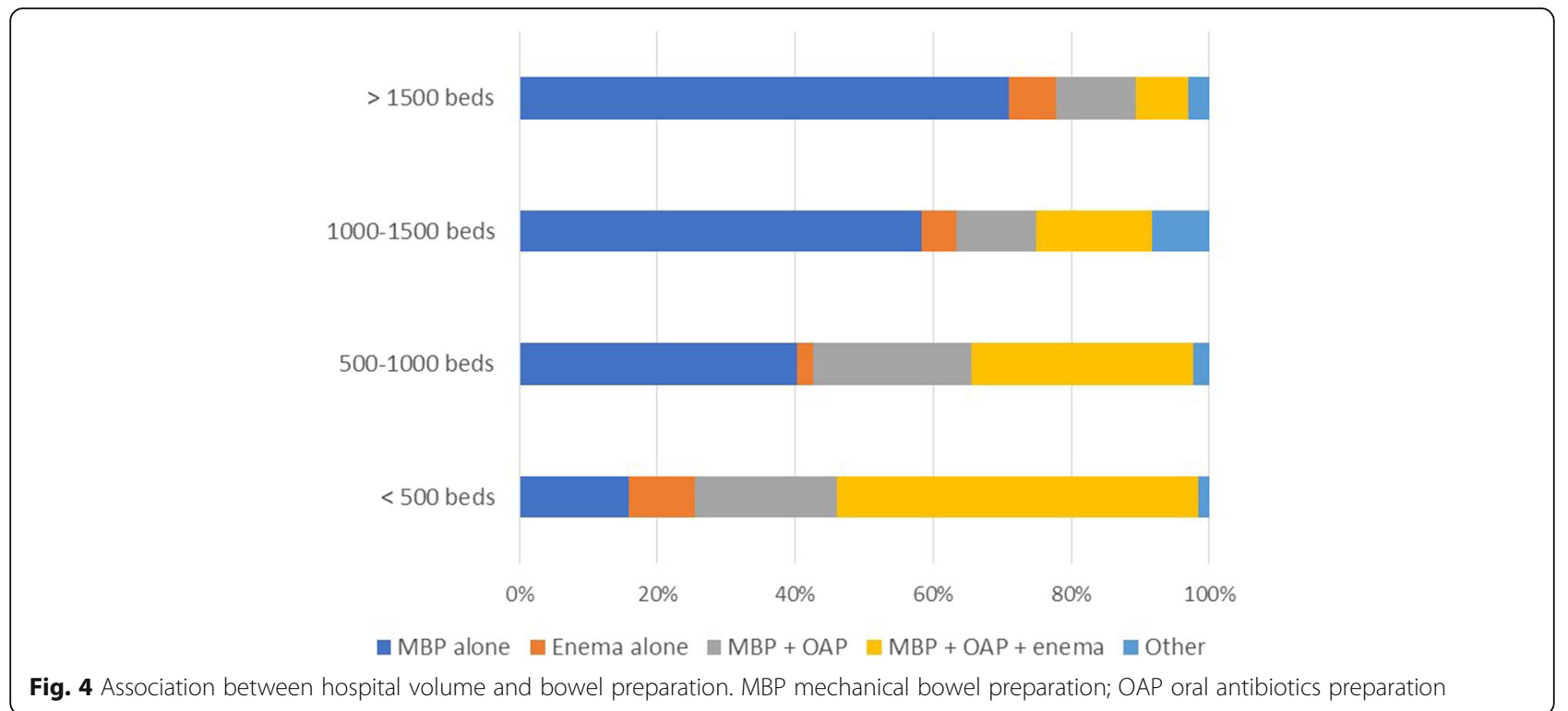

for intestinal obstruction is common (71.3\%). Although enema could stimulate the colon to contract and eliminate stool, it may cause serious adverse events, such as perforation or metabolic derangement [26]. Our findings should lead to a careful consideration of appropriate bowel preparation to intestinal obstruction.

\section{Conclusions}

In conclusion, this survey provides an adequate response from the CSCC members, describing the preoperative bowel preparation in current practices. Regarding the respondent's age, hospital, and resection volume, as well as the percentage of minimally invasive resections, the study shows that there is no current standardization of preoperative bowel preparation among colorectal surgeons in China, especially concerning the use of oral or intravenous antibiotic prophylaxis. Therefore, we recommend the CSCC should use these results to develop new protocols for multicenter trials and provide more definitive answers.

\section{Additional file}

Additional file 1: A 19-question paper-based survey. (DOCX 18 kb)

\section{Abbreviations}

ACS-NSQIP: American College of Surgeons National Surgical Quality Improvement Program; ASCRS: American Society of Colon and Rectal Surgeons; CSCC: Chinese Society of Colorectal Cancer; ESCP: European Society of Coloproctology (ESCP); MBP: Mechanical bowel preparation; OAP: Oral antibiotics preparation; SAGES: Society of American Gastrointestinal and Endoscopic Surgeons

\section{Funding}

This study was supported by the Beijing Municipal Science \& Technology Commission (No. Z161100000116090); the National Key Research and Development Program of the Ministry of Science and Technology of China (No. 2016YFC0905303); the CAMS Innovation Fund for Medical Sciences
(CIFMS) (No.2016-12M-1-001); and the Beijing Science and Technology Program (No. D17110002617004).

Availability of data and materials

Please contact the author for data requests.

\section{Authors' contributions}

$\mathrm{ZL}, \mathrm{MY}, \mathrm{ZZ}$, and $\mathrm{XW}$ are responsible for the design, acquisition of data, analysis and interpretation of data, drafting of the manuscript, critical revision, and final approval. GX and ZJ are responsible for the acquisition of data, critical revision, and final approval. HC, SW, and JQ are responsible for the critical revision and final approval. All authors read and approved the final manuscript.

Ethics approval and consent to participate

Not applicable.

\section{Consent for publication}

Not applicable.

\section{Competing interests}

The authors declare that they have no competing interests.

\section{Publisher's Note}

Springer Nature remains neutral with regard to jurisdictional claims in published maps and institutional affiliations.

Received: 14 May 2018 Accepted: 4 July 2018

Published online: 09 July 2018

\section{References}

1. Slim K, Kartheuser A. Mechanical bowel preparation before colorectal surgery in enhanced recovery programs: discrepancy between the American and European guidelines. Dis Colon Rectum. 2018;61:e13-4.

2. Parthasarathy M, Greensmith M, Bowers D, Groot-Wassink T. Risk factors for anastomotic leakage after colorectal resection: a retrospective analysis of 17 518 patients. Color Dis. 2017;19:288-98.

3. Midura EF, Jung AD, Hanseman DJ, Dhar V, Shah SA, Rafferty JF, Davis BR, Paquette IM. Combination oral and mechanical bowel preparations decreases complications in both right and left colectomy. Surgery. 2018;163:528-34.

4. Mik M, Berut M, Trzcinski R, Dziki L, Buczynski J, Dziki A. Preoperative oral antibiotics reduce infections after colorectal cancer surgery. Langenbeck's Arch Surg. 2016;401:1153-62.

5. Anjum N, Ren J, Wang G, Li G, Wu X, Dong H, Wu Q, Li J. A randomized control trial of preoperative oral antibiotics as adjunct therapy to systemic antibiotics for 
preventing surgical site infection in clean contaminated, contaminated, and dirty type of colorectal surgeries. Dis Colon Rectum. 2017;60:1291-8.

6. Vo E, Massarweh NN, Chai CY, Tran Cao HS, Zamani N, Abraham S, Adigun $\mathrm{K}$, Awad SS. Association of the addition of oral antibiotics to mechanical bowel preparation for left colon and rectal cancer resections with reduction of surgical site infections. JAMA Surg. 2018;153:114-21.

7. Ohman KA, Wan L, Guthrie T, Johnston B, Leinicke JA, Glasgow SC, Hunt SR, Mutch MG, Wise PE, Silviera ML. Combination of oral antibiotics and mechanical bowel preparation reduces surgical site infection in colorectal surgery. J Am Coll Surg. 2017;225:465-71.

8. Garfinkle R, Abou-Khalil J, Morin N, Ghitulescu G, Vasilevsky CA, Gordon P, Demian $\mathrm{M}$, Boutros $\mathrm{M}$. Is there a role for oral antibiotic preparation alone before colorectal surgery? ACS-NSQIP analysis by coarsened exact matching. Dis Colon Rectum. 2017;60:729-37.

9. Klinger AL, Green H, Monlezun DJ, Beck D, Kann B, Vargas HD, Whitlow C, Margolin D. The role of bowel preparation in colorectal surgery: results of the 2012-2015 ACS-NSQIP data. Ann Surg. 2017; https:/doi.org/10.1097/SLA.0000000000002568.

10. Nichols RL, Smith JW, Garcia RY, Waterman RS, Holmes JW. Current practices of preoperative bowel preparation among North American colorectal surgeons. Clin Infect Dis. 1997;24:609-19.

11. Cannon JA, Altom LK, Deierhoi RJ, Morris M, Richman JS, Vick CC, Itani KM, Hawn MT. Preoperative oral antibiotics reduce surgical site infection following elective colorectal resections. Dis Colon Rectum. 2012;55:1160-6.

12. Scarborough JE, Mantyh CR, Sun Z, Migaly J. Combined mechanical and oral antibiotic bowel preparation reduces incisional surgical site infection and anastomotic leak rates after elective colorectal resection: an analysis of Colectomy-Targeted ACS NSQIP. Ann Surg. 2015;262:331-7.

13. Contant CM, Hop WC, van't Sant HP, Oostvogel HJ, Smeets HJ, Stassen LP, Neijenhuis PA, Idenburg FJ, Dijkhuis CM, Heres P, van Tets WF, Gerritsen JJ, Weidema WF. Mechanical bowel preparation for elective colorectal surgery: a multicentre randomised trial. Lancet. 2007;370:2112-7.

14. McCoubrey AS. The use of mechanical bowel preparation in elective colorectal surgery. Ulster Med J. 2007;76:127-30.

15. Bucher P, Gervaz P, Soravia C, Mermillod B, Erne M, Morel P. Randomized clinical trial of mechanical bowel preparation versus no preparation before elective left-sided colorectal surgery. Br J Surg. 2005;92:409-14.

16. Jung B, Påhlman L, Nyström PO, Nilsson E; Mechanical Bowel Preparation Study Group. Multicentre randomized clinical trial of mechanical bowel preparation in elective colonic resection. Br J Surg 2007;94:689-695.

17. Zmora O, Wexner SD, Hajjar L, Park T, Efron JE, Nogueras JJ, Weiss EG. Trends in preparation for colorectal surgery: survey of the members of the American Society of Colon and Rectal Surgeons. Am Surg. 2003;69:150-4.

18. Solla JA, Rothenberger DA. Preoperative bowel preparation. A survey of colon and rectal surgeons. Dis Colon Rectum. 1990;33:154-9.

19. Watanabe M, Murakami M, Aoki T, Takahashi K, Yasuno M, Masaki T, Itabashi M, Yoshimatsu K, Saida Y, Funahashi K, Kan H, Ota M. The current perioperative care in elective colorectal surgery in Japan: a questionnaire survey of members of the Tokyo Colon Seminar Committee. Nihon Daicho Komonbyo Gakkai Zasshi. 2015;68:391-402.

20. Slim K, Martin G. Mechanical bowel preparation before colorectal surgery. Where do we stand? J Visc Surg. 2016;153(2):85-7.

21. Carmichael JC, Keller DS, Baldini G, Bordeianou L, Weiss E, Lee L, Boutros M, McClane J, Feldman LS, Steele SR. Clinical practice guidelines for enhanced recovery after colon and rectal surgery from the American Society of Colon and Rectal Surgeons and Society of American Gastrointestinal and Endoscopic Surgeons. Dis Colon Rectum. 2017;60:761-84.

22. Devane LA, Proud D, O'Connell PR, Panis Y. A European survey of bowel preparation in colorectal surgery. Color Dis. 2017;19:0402-6.

23. Drummond RJ, McKenna RM, Wright DM. Current practice in bowel preparation for colorectal surgery: a survey of the members of the Association of Coloproctology of GB \& Ireland. Color Dis. 2011;13:708-10.

24. Chan MY, Foo CC, Poon JT, Law WL. Laparoscopic colorectal resections with and without routine mechanical bowel preparation: A comparative study. Ann Med Surg (Lond). 2016;9:72-6.

25. Koller SE, Bauer KW, Egleston BL, Smith R, Philp MM, Ross HM, Esnaola NF. Comparative effectiveness and risks of bowel preparation before elective colorectal surgery. Ann Surg. 2018;267:734-42.

26. Niv G, Grinberg T, Dickman R, Wasserberg N, Niv Y. Perforation and mortality after cleansing enema for acute constipation are not rare but are preventable. Int J Gen Med. 2013;6:323-8.

Ready to submit your research? Choose BMC and benefit from:

- fast, convenient online submission

- thorough peer review by experienced researchers in your field

- rapid publication on acceptance

- support for research data, including large and complex data types

- gold Open Access which fosters wider collaboration and increased citations

- maximum visibility for your research: over $100 \mathrm{M}$ website views per year

At BMC, research is always in progress.

Learn more biomedcentral.com/submissions 